\title{
AS FORÇAS POR TRÁS DOS ACORDOS: A LUTA DOS PETROLEIROS PARA MANTER OS SEUS DIREITOS
}

\author{
FORCES BEHIND AGREEMENTS: THE OIL WORKERS STRUGGLE TO
}

PRESERVATION OF THEIR RIGHTS

Danilo Mendes ${ }^{1}$

\section{RESUMO}

No Brasil, a malha de proteção social foi sendo costurada pelo poder da classe trabalhadora muito antes que as legislações trabalhista e sindical viessem a ser unificadas por Vargas entre os anos 1930-1940. Analisando a trajetória dos/as trabalhadores/as da Petrobras, argumentamos que a efetividade, ou não, dessas legislações dependeram da força desse grupo construir seus próprios direitos e benefícios. Esse grupo, recentemente, vinha mantendo um avançado acordo coletivo conquistado na campanha reivindicatória de 2013, mas no ano de 2019 teve que enfrentar uma ofensiva precarizante por parte da Petrobras. Por meio de análise documental (matérias de imprensa sindical e comercial, documentos oficiais e acordos coletivos) e de análise de discursos, reconstruímos as relações por trás do acordo de 2019. Os resultados mostram que a experiência e a tradição de luta, associadas ao poder de organização dos/as trabalhadores/as da Petrobras, possibilitaram resistir a uma acentuada perda de direitos.

Palavras-chave: direitos do trabalho, sindicalismo petroleiro, luta de classes, precarização, política industrial.

\begin{abstract}
In Brazil, social protection has been built by the working class power earlier than the labor and union legislations were unified by President Getúlio Vargas between 1930 and 1940. By analyzing the oil workers trajectory, we argue that the effectiveness of those legislations depends on the strength such working class has to assure its own rights and benefits. Currently, oil workers have kept an advanced collective agreement earned by the campaign for demands in 2013. Nevertheless, they had to face an attack delivered by Petrobras in 2019, which led them to labor insecurity. This paper analyzes documents (articles from union and commercial press), as well as speeches in order to restore the relations behind the 2019 agreement. The study results set forth experience and struggle tradition, associated to the organizing power of that class, which made possible for them to resist to an increasing loss of rights.
\end{abstract}

Keywords: labor rights, oil unionism, class struggle, precariousness, industrial policy.

Journal of Economic Literature: I110 - Analysis of Health Care Markets; J5 - Labor-Management Relations, Trade Unions, and Collective Bargaining; K310 - Labor Law; L520 Industrial Policy; Sectoral Planning Methods; P160 - Capitalist Systems: Political Economy.

\footnotetext{
1 Doutorando no Programa de Pós-Graduação em Sociologia da UFSCar e pesquisador do Laboratório de Estudos sobre Trabalho, Profissões e Mobilidades (LEST-M). O presente trabalho foi realizado com apoio da Coordenação de Aperfeiçoamento de Pessoal de Nível Superior - Brasil (CAPES) - Código de Financiamento 001.
} 
Muito custou à classe trabalhadora brasileira fazer-se reconhecer como sujeito político (GOMES, 2005). Foi durante a I República que as primeiras leis sociais foram instituídas por força do protesto trabalhista. Inicialmente, a malha de proteção social foi sendo tecida pelas categorias laborais com maior poder de barganha, o que se tornou um padrão para o avanço da regulamentação das relações de trabalho. Assim, as categorias ocupacionais mais fortes conseguiram proteção antes que as menos organizadas. Esse foi o caso dos trabalhadores e trabalhadoras rurais e das empregadas domésticas que alcançaram os direitos básicos do trabalho apenas nas décadas de 1960 e 1970, respectivamente (SANTOS, 1979), décadas depois que algumas categorias de trabalhadores empregados na indústria, por exemplo.

Como a conquista de direitos seguiu o modelo categorial ${ }^{2}$, uma importante parcela das legislações trabalhista e sindical tem efetividade, ou não, conforme a força de cada categoria laboral que, em alguns casos, pode conquistar direitos e benefícios mais avançados que os previstos na lei.

Esse é o caso dos/as trabalhadores/as da Petrobras. Situado na indústria de petróleo e gás, esse grupo está exposto a altos índices de acidentes ${ }^{3}$, que, quando não são fatais, provocam sequelas graves, e uma alta frequência de doenças crônicas com elevados custos de assistências médica e farmacêutica. A diferenciada especialização técnica, desse grupo, associada aos contínuos riscos à saúde, impõem a necessidade de direitos específicos e não previstos pela CLT4. Esses vêm a ser garantidos pela força da ação coletiva do grupo que historicamente resiste às tentativas de heteronomização da construção de seus direitos. Expressão disso é a prática da instituição de seus direitos por meio do Acordo Coletivo de Trabalho (ACT), negociado diretamente com a empresa, sem intermediários.

Até 2019, vinha se tornando uma tradição entre os petroleiros e a Petrobras, negociarem um ACT com validade de dois anos. Desde 2013, quando a categoria conquistou o melhor acordo de sua história (PARANHOS, 2016), o ACT tinha sido renovado em 2015 e em 2017, apenas as cláusulas econômicas, sujeitas aos efeitos da inflação, eram atualizadas nos intervalos desses anos. Em 2019, pôde-se observar um processo atípico, as negociações extrapolaram

2 Seguimos aqui a observação seminal de Wanderley Guilherme dos Santos que, examinando o histórico da legislação social no Brasil, notou que "a diferenciação social e o peso relativo de uma categoria ocupacional, no processo de acumulação, são insuficientes para produzir consideráveis mudanças de curso na produção de políticas governamentais, se não são acompanhados por simultânea estruturação organizacional". Com efeito, a tradição brasileira vem mostrando que as mudanças legislativas, bem como as leis e os acordos, dependem, decisivamente, do poder organizacional de cada categoria: "é a agitação camponesa que se deflagra na segunda metade da década dos 50 que irá provocar a atenção do poder público para os problemas de acumulação e equidade na área rural, refletida na promulgação da Lei 4.214, de 2 de março de 1963, sob a solene denominação de Estatuto do Trabalhador Rural, o qual, não obstante, revelou ser apenas outro exemplo de manipulação simbólica de estatutos legais, uma vez que não lhe foram definidos os meios materiais - financeiros e outros - de operação efetiva" (SANTOS, 1979, p. 33-34).

3 Em 16 de agosto de 1984, ocorreu o maior acidente da história da indústria de petróleo e gás no país. Morreram 37 petroleiros e 19 ficaram feridos na queda de uma baleeira que transportava os trabalhadores na plataforma de Enchova na Bacia de Campos no estado do Rio de Janeiro. Disponível em: < https://www.fup.org.br/ultimasnoticias/item/24290-35-anos-do-acidente-de-enchova-pior-acidente-de-trabalho-da-petrobras; https://www.fup. org.br/ultimas-noticias/item/24291-ato-no-heliporto-do-farol-nesta-manha-lembra-35-anos-da-tragedia-deenchova.. >. Acesso em: 16 abr. 2020.

4 O Acordo Coletivo de Trabalho (ACT) dos empregados da Petrobras contém benefícios específicos pelas seguintes razões: “A primeira e mais importante é que ele é coletivo e negociado pelos representantes sindicais para todos os trabalhadores do Sistema Petrobras. Composto por direitos específicos dos riscos dessa profissão, que foram conquistados ao longo dos anos, que a CLT não consegue garantir. Nosso ACT é a segurança que iremos voltar para nossa família em segurança, após uma jornada de trabalho".Disponível em: <https://www. fup.org.br/ultimas-noticias/item/24276-petrobras-propoe-fim-do-acordo-coletivo-de-trabalho.>. Acesso em: 16 abr. 2020. 
o prazo de 31 de agosto. Tendo sido iniciadas pelas Federações petroleiras ${ }^{5}$ em 15 de maio, as tratativas foram encerradas apenas em 4 de novembro. Em meio a uma tensa campanha reivindicatória, os petroleiros conseguiram impedir o desmantelamento da proteção social, historicamente construída pelo grupo.

A hipótese deste artigo é que o acordo coletivo de trabalho não apenas reproduz os direitos da malha de proteção social constituída, em parte, pelas legislações trabalhista e sindical $^{6}$, mas por força da tradição do modelo categorial de pactuação das relações de trabalho, entre empresa e empregados, os acordos podem conter direitos e benefícios mais avançados que o previsto na legislação. Essa possibilidade está colocada para todas as categorias, mas sua realização é particular, pois depende do poder organizacional de cada grupo. Ou seja, entre a possibilidade e a realização dos direitos, o poder sindical é o recurso decisivo ${ }^{7}$.

Essa proposição pode ser mais bem compreendida à luz da abordagem dos recursos de poder apresentada por Stefan Schmalz, Carmen Ludwig e Edward Webster (2018) ${ }^{8}$. Esses autores incorporaram as ideias de poder estrutural e poder associativo, sistematizadas por Erik Olin Wright (2000) e Beverly Silver (2003), com a finalidade de sugerir um modelo de análise da ação sindical centrada na consideração dos recursos de poder (estrutural, associativo, institucional e social).

O poder estrutural está relacionado à inserção econômica dos/as trabalhadores/ as e se manifesta como poder de barganha no local de trabalho e no mercado de trabalho. "Os assalariados em setores de alta produtividade do trabalho, com processos de produção altamente integrados ou em importantes ramos de exportação, têm um grau particularmente alto de poder de barganha no local de trabalho" (SCHMALZ; LUDWIG; WEBSTER, 2018, p. 116). Esse é o caso dos/as trabalhadores/as da Petrobras, uma vez que o setor de petróleo e gás é considerado essencial em uma economia que depende de combustíveis fósseis para garantir a circulação de bens e pessoas. Logo, toda greve petroleira coloca no horizonte a possibilidade do desabastecimento, o que significa um importante recurso de poder para esse grupo - embora

5 Os petroleiros são representados por sindicatos que formam duas Federações. A Federação Única dos Petroleiros (FUP) foi fundada em 1994 e a Federação Nacional dos Petroleiros (FNP) formou-se em 2006, reunindo sindicatos dissidentes da FUP.

6 Inspiramo-nos, aqui, na tese do sistema legislado de relações de trabalho de Eduardo Noronha (2000), assim classificado em razão da "forte presença da lei na estruturação do mercado de trabalho" brasileiro. Segundo essa tese, as relações de trabalho são negociadas em três espaços normativos: "o legislativo, a contratação coletiva e as normas das empresas definidas unilateralmente pelos empregadores" (NORONHA, 2000, p. 241). Embora reconheçamos a "forte presença da lei na estruturação do mercado de trabalho" brasileiro, cabe lembrar que nosso argumento principal reforça a ideia de que a lei, a contratação coletiva e as normas têm efetividade, ou não, segundo o poder de organização dos trabalhadores e das trabalhadoras, em geral, e de categorias ocupacionais em particular. Ou seja, o conflito de classes entendido como processo (THOMSPON, 2019) é central para o nosso argumento.

7 Sobre o poder sindical, cabe observar que o poder público reconheceu a organização de sindicatos profissionais no Brasil em 1907. Se o poder dos sindicatos não se fez manifestar de imediato, não se deve ao poder restritivo da lei, mas à força relativa dos trabalhadores: "os limites de ação de qualquer organização social, definidos por lei, serão ou não respeitados por força do peso político dos grupos que Ihes dão vida, antes que pela obediência formal aos estatutos legais" (SANTOS, 1979, p. 21).

8 A expressão original é "power resources approach". Essa expressão nomeia o pressuposto dessa abordagem: “a premissa básica de que os trabalhadores podem defender com sucesso seus interesses por meio da mobilização coletiva de recursos de poder na relação estruturalmente assimétrica e antagônica entre capital e trabalho". Esse modelo foi desenvolvido por meio de pesquisas empíricas sobre ação sindical em diferentes países, de pelo menos quatro continentes (África, América, Ásia e Europa), e incorporou, ao mesmo, um conjunto de referências cuja origem remonta aos anos 1960 e 1970 "com a redescoberta da classe como uma categoria analítica". Nesse contexto, o "ressurgimento do conflito industrial, bem como a ascensão da Nova Esquerda e do movimento estudantil, destruiu a 'tese do fim da ideologia', desafiando a hegemonia do pluralismo, do neocorporativismo e do marxismo ortodoxo” (SCHMALZ, S. LUDWIG, C. WEBSTER, E., 2018, p. 114-116). 
a lei de greve ${ }^{9}$ enquadre essa categoria como prestadora de serviço essencial, o que em tese lhe proíbe efetuar uma paralisação total.

No caso de categorias ocupacionais, como os petroleiros, as próprias características do poder estrutural favorecem o desenvolvimento do poder associativo, este último entendido como a capacidade de agir coletivamente. Assim, integrada desde o processo de trabalho, essa categoria apresenta forte capacidade de ação coletiva com destacado impacto político (BRANT, 1990; ROMÃO, 2006). O processo organizacional construído desde o local de trabalho, por sua vez, sustenta a organização dos/as trabalhadores/as da Petrobras em sindicatos e federações que atuam com significativa força em diferentes esferas. Na esfera institucional, desfere seu poder afirmando-se como um sujeito ativo na produção dos acordos que cobrem as especificidades de suas relações de trabalho. Também é capaz de aliar-se a movimentos sociais fortalecendo a face social do poder organizacional dos trabalhadores.

Como sugere, ainda, a análise dos recursos de poder, cada um desses poderes não é exercido isoladamente, eles existem de modo variável segundo a situação ocupacional de cada grupo de trabalhadores e se reforçam mutuamente, também, de acordo com o contexto social mais geral. "Como o contexto histórico, político e social difere, o uso do poder também assume diferentes formas [...].” (SCHMALZ; LUDWIG; WEBSTER, 2018, p. 124).

A mobilização dos recursos de poder dos/as trabalhadores/as empregados na Petrobras conteve a ofensiva potencialmente precarizante embutida nas propostas de acordo da empresa estatal durante as negociações do ACT em 2019. Os recursos de poder desse grupo de trabalhadores/as foram historicamente construídos e mobilizados, seja em períodos democráticos (1945-1964 e 1985-2019), seja em tempos de ditadura (1964-1985). A segunda parte deste artigo resgata, brevemente, o histórico de luta do grupo sob os diferentes governos desde a década de 1950. Nas duas partes seguintes, descrevemos o tenso processo de negociação do ACT de 2019 com destaque para o foco das tensões nos capítulos referentes à assistência médica e à representação sindical. Em seguida, analisamos o caráter político da gestão da Petrobras e os seus potenciais efeitos sobre as relações de trabalho.

\section{O HISTÓRICO DO PROTESTO PETROLEIRO}

Paulínia: petróleo e política (1990), pesquisa conduzida por Vinícius Caldeira Brant, tornou-se um clássico sobre o sindicalismo petroleiro. A questão colocada por esse estudo diz respeito ao significado da ação sindical petroleira. Seria ela meramente defensiva e/ou reativa?

Brant (1990) parte da constatação de que a situação dos petroleiros em uma empresa estatal de um setor econômico estratégico, muito sensível às orientações do governo federal e às razões de Estado, politizaria de modo direto o sindicalismo desse grupo:

A conjugação entre objetivos imediatos, referentes às condições de trabalho e salários, e objetivos políticos mais gerais, atinentes à organização do Estado, encontra no sindicalismo petroleiro um cenário privilegiado. Por situar-se na Petrobras, empresa modelo das propostas ao mesmo tempo estatizantes e democratizantes do pós-

\footnotetext{
9 Trata-se da Lei $\mathrm{n}^{\circ} 7.783$, de 28 de junho de 1989, que dispõe sobre o exercício do direito de greve, limitando-o no caso de atividades essenciais. "Art. 10 - São considerados serviços ou atividades essenciais: I - tratamento e abastecimento de água; produção e distribuição de energia elétrica, gás e combustíveis; [...]. Art. 11 - Nos serviços ou atividades essenciais, os sindicatos, os empregadores e os trabalhadores ficam obrigados, de comum acordo, a garantir, durante a greve, a prestação dos serviços indispensáveis ao atendimento das necessidades inadiáveis da comunidade.” Disponível em: <http://www.planalto.gov.br/ccivil_03/leis/17783.HTM.>. Acesso em: 8 set. 2020 .
} 
guerra; articular a defesa do patrimônio público com reivindicações sobre o controle da gestão empresarial pelos trabalhadores; por arrostar os dilemas entre interesses comuns ao conjunto diferenciado dos vários setores do operariado e interesses daqueles que se situam no polo mais moderno da produção; por atuar em área estratégica no ramo energético; por questionar, enfim, políticas estatais centralizadas que afetam a todos - o exame da atuação dos petroleiros já se revelaria relevante (BRANT, 1990, p. 15).

A organização dos petroleiros se destacaria, além disso, pelo fato de zelar por uma relação mais democrática entre base e direção sindical. E, ainda, por despontar como uma das categorias mais atuantes para a fundação da Central Única dos Trabalhadores (CUT) nos níveis regional e nacional.

Brant (1990) nos faz compreender que o contexto específico da ação sindical desse grupo entrelaça a demanda ordinária (a luta incontornável por melhores condições de trabalho, intrínseca aos sindicatos) com o jogo da política, cuja iniciativa pertence ao governo. Assim, embora a relação imediata seja com a empresa, os petroleiros são levados a tomar uma posição favorável ou contrária aos direcionamentos que extrapolam o espaço fabril, pois em última instância são determinados pela política do governo federal.

Quando se analisam, por exemplo, as pautas de negociação [...] verifica-se que os resultados materiais imediatos ocupam o primeiro plano das mobilizações. Não obstante, o confronto objetivo com as políticas governamentais é inevitável, não só porque a Petrobras é uma empresa estatal, sujeita a diretrizes de alçadas superiores, mas principalmente porque as reivindicações trabalhistas de qualquer categoria afetam os planos de regulação geral da economia (BRANT, p. 143).

Os eventos desencadeados pela greve dos petroleiros de 1983 dão suporte a esses argumentos.

Em um contexto econômico caracterizado por expressivo déficit público, o governo federal recorreu a empréstimos de instituições financeiras internacionais, dentre elas o Fundo Monetário Internacional (FMI). Essas instituições condicionaram o acesso ao crédito com a adoção de um conjunto de reformas, visando reorganizar o setor público. Desse modo, o governo Figueiredo mandou ao Congresso uma série de reformas cujas implicações seriam de perdas de direitos dos trabalhadores de empresas estatais.

Maio de 1983, o governo mandou ao Congresso Nacional o decreto-lei $\mathrm{n}^{\mathrm{o}} 2025$. Por ele cortavam-se todos os benefícios dos servidores das estatais: abono de férias, promoções, auxílios para alimentação e transporte, salário adicional anual, participação nos lucros, recompensas das chefias, dentre outros; estabeleceram-se prazos para um corte total de dez por cento do efetivo das empresas e proibiram-se novas contratações e investimentos por um ano (BRANT, p. 21).

Após o decreto, os petroleiros se organizaram para enfrentar as consequências dessas medidas e em 16 de junho aprovaram estado de greve. Em seguida (29 de junho), o governo alterou o decreto, mas os/as trabalhadores/as ainda viram como ameaçadoras suas implicações.

A margem de manobra de uma refinaria, no tocante à redução de custos, é bastante reduzida uma vez que o preço da matéria-prima básica, o petróleo, é determinado internacionalmente. O alvo preferencial para o corte de despesas operacionais, segundo o sindicato, recairia inevitavelmente sobre o corpo de funcionários. Como, nessa nova versão, o decreto-lei determinava o fim de benefícios exclusivamente para os novos admitidos, a ameaça passava a ser, então, a rotatividade no emprego. Nova 
assembleia [...] ratifica o dia de paralisação com apenas quatro votos contra e mais de setecentos a favor. A pauta: a) garantia do emprego; b) revogação do decreto-lei $\mathrm{n}^{\circ}$ 2036 (BRANT, p. 22).

Assim, os petroleiros entraram em greve no dia 5 de julho. Dois dias depois os sindicatos sofreram intervenção federal e os seus dirigentes foram cassados.

Os fatos que compõem o quadro geral dessa greve, bem como a exposição dos motivos de cada agente, explicitam o inescapável caráter político da ação sindical desse grupo. No contexto de ascensão do sindicalismo (ALMEIDA, 1996) e das lutas sociais que colocaram a desigualdade social e a universalização dos direitos sociais na ordem do dia (OLIVEIRA, 2007), a ação sindical dos petroleiros extrapolou a predição teórica da consciência econômica (LÊNIN, 1978).

No entanto, o caráter político da mobilização petroleira não era uma novidade histórica. Esse grupo mobilizou-se por motivos políticos já na década de 1950. Em 1959, por exemplo, os/ as trabalhadores/as da Petrobras conseguiram mudar o modo de recrutamento dos funcionários da empresa, que passou a ser realizado por meio de concursos públicos. Nos primeiros anos da década de 1960 os petroleiros organizaram paralisações para interferir na nomeação para cargos de direção da Petrobras, chegando a emplacar dois nomes na presidência da empresa (ROMÃO, 2006).

Porém, a atuação política dos petroleiros ganhou reconhecimento público entre a campanha da legalidade e a resistência ao golpe de Estado de 1964.

Em 1961, com a renúncia do Presidente da República Jânio Quadros, o SindipetroBA faz greve de dois dias pela legalidade e lança nota pública, com o mesmo intento, em conjunto com o STIEP-BA e o Sindipetro Cubatão. No ano seguinte, 1962, os petroleiros fazem greve junto a outras categorias, exigindo a nomeação de um "Gabinete Democrático Nacionalista". Param nessa greve a Bahia, Cubatão, REDUC, a Refinaria de Manguinhos, o terminal da Guanabara, o escritório no Rio de Janeiro e Belém. Em 1964 os petroleiros participam da tentativa da CGT em resistir ao golpe militar (ROMÃO, 2006, p. 183-184).

Nos primeiros anos da ditadura, a categoria promoveu greves de fome (1966 e 1968) como forma de protesto. As mobilizações foram retomadas no final da década de 1970. Em 1977, insurgiu-se contra a manipulação dos índices de inflação e, no ano de 1978, promoveu uma paralisação em solidariedade à greve dos metalúrgicos do $\mathrm{ABC}$ paulista.

A década de 1980 foi marcada pela ascensão das greves. Para os petroleiros, a greve de 1983 se inscreve em uma tradição iniciada nas décadas anteriores pelas primeiras gerações de trabalhadores da indústria de petróleo e gás. Às experiências das gerações pioneiras, somou-se a experiência da nova geração de militantes petroleiros, que, ainda em 1983, participaria da greve geral em julho e da fundação da CUT em agosto. Em seguida, na luta pela reintegração dos companheiros demitidos após a greve contra as reformas do governo Figueiredo, aprofundou-se a percepção de que a luta por seus interesses imediatos os atrelavam à esfera do poder político. Os petroleiros protestaram junto a parlamentares contra as medidas arbitrárias que provocaram as demissões e, aos poucos, foram conseguindo a readmissão dos trabalhadores dispensados (BRANT, 1990).

Na segunda metade da década de 1980, a categoria parou contra as políticas inspiradas no receituário do FMI e as implicações do Plano Cruzado II (1986), por melhores salários (1987 
e 1988) e pela greve geral ocorrida nos dias 14 e 15 de março de 1989. Ao todo, na "década das greves",os petroleiros ficaram 38 dias parados $^{10}$.

Em todos os anos da década de1990, com exceção de 1998, houve paralisação nacional dos empregados da Petrobras. Em 1995 ocorreu uma greve histórica entre 2 de maio e 3 de junho, o motivo dominante foi o não cumprimento do acordo coletivo. O presidente Fernando Henrique Cardoso decretou a ocupação das refinarias pelas forças armadas e a greve foi encerrada (ROMÃO, 2006).

$\mathrm{Na}$ década seguinte, os petroleiros foram se recuperando dos ataques sofridos durante a "década neoliberal" (ALVES, 2002; CARDOSO, 2003). Sob os governos do Partido dos Trabalhadores (PT) os petroleiros não deixaram de protestar, foram 18 dias de paralisações com a base nacional unificada. Nessa década, a Petrobras ampliou os investimentos (CERQUEIRA, 2016) fortalecendo a expansão dos empregos formais, uma das marcas do período (KREIN; TEXEIRA, 2016). Ao mesmo tempo, as privatizações de empresas subsidiárias da Petrobras foram arrefecendo. Esses fatores fizeram a Federação Única dos Petroleiros (FUP) se alinharem aos governos do PT (LOUREIRO; TROJBICZ, 2018). Contudo, isso não significou uma adesão acrítica, quando o governo tentou retomar os leilões de campos de petróleo, os petroleiros organizaram expressiva mobilização contrária (MENDES, 2019). Em 2013, os petroleiros paralisaram as atividades por sete dias consecutivos em todo país contra o leilão do campo de Libra. Ainda no período petista, mas com a Petrobras sob uma nova gestão ${ }^{11}$, no ano de 2015 os petroleiros propuseram a criação de um Grupo de Trabalho para

\begin{abstract}
negociar junto à Petrobras caminhos e alternativas para evitar a venda de ativos, manter os empregos e investimentos. A Petrobras ignorou os petroleiros por mais de cem dias [...]. A Federação Única dos Petroleiros fez uma greve de advertência no dia 24 de julho de 2015 em função do impasse nas negociações do Acordo Coletivo de Trabalho. Nas rodadas de negociação de todas as cláusulas do Acordo Coletivo 20152017, a Petrobras sinalizou cortar direitos. Os sindicalistas petroleiros ao mesmo tempo quiseram tanto negociar o Acordo Coletivo de Trabalho quanto a pauta política para a Petrobras através da Pauta Pelo Brasil. Isto reforçou e sinalizou a preocupação do movimento sindical petroleiro [...] com os interesses sociais mais amplos [...]. A greve de 2015 teve início em $1 .^{\circ}$ de novembro de 2015 e em alguns sindicatos foi feita até o dia 20 de novembro de 2015 (PARANHOS, 2016, p. 116).
\end{abstract}

Já sob o governo Temer, os petroleiros promoveram uma paralisação nacional contra a nova gestão da Petrobras, que iniciou o plano de redução do endividamento da empresa por meio de cortes de investimentos. Em 2017, os/as trabalhadores/as participaram da greve geral e

${ }_{10}$ Os dados sobre as greves dos petroleiros entre os anos de 1977 até 2009 foram retirados de um documento do SAG/DIEESE.

11 Em fevereiro de 2015, Aldemir Bendine substituiu Graça Foster na presidência da Petrobras. Bendine assumiu a gestão para resolver a "crise de credibilidade" que atingiu a empresa quando três de seus diretores foram denunciados por atos de corrupção pela Operação Lava Jato. Com efeito, "a empresa responsável pela auditoria dos seus balanços, Price Water house Coopers, recusou-se a aprovar seu balanço contábil do terceiro trimestre de 2014 e exigiu investigações internas para comprovar a extensão das perdas ocorridas com as primeiras denúncias de subornos na companhia." Em seguida, “as empresas de classificação de riscos de crédito Moody's, Standard\& Poor's e Fitch rebaixaram a nota de crédito da Petrobras". Para recuperar a credibilidade, a nova gestão passou a "realizar ajustes em seu nível de investimentos, adequando-os às necessidades de cumprimento dos serviços anuais da dívida, e de desenvolver um extenso programa de venda de ativos". Essa estratégia, no entanto, limou os investimentos da empresa com forte impacto sobre o mercado de trabalho: "Em termos de emprego, 17,8 mil funcionários próprios saíram da companhia, de 2013 a 2016. Foram ainda desligados, desde dezembro de 2014, 114 mil pessoas prestadoras de serviços à Petrobras, envolvendo trabalhadores em serviços de obras, montagens, administrativos e operacionais. Nos estaleiros, o emprego caiu de 82,5 mil pessoas, em 2014, para 35 mil, em dezembro de 2016" (MORAIS, 2017, p. 20-21). 
organizou uma campanha (Projeto para mudar o Brasil) em defesa de uma política de expansão dos investimentos da Petrobras para criar empregos e renda para os trabalhadores. Apesar das tensões, a FUP conseguiu renovar o ACT de 2015, preservando os direitos adquiridos no período anterior. O mesmo não ocorreu em 2019.

\section{O PROCESSO DE NEGOCIAÇÃO DO ACT 2019-2020.}

No dia 15 de maio de 2019 os/as representantes/os dos empregados da Petrobras ${ }^{12}$ deram início ao processo de negociação do ACT, que venceria em 31 de agosto. Naquela data entregaram à empresa a pauta de reivindicações que, em síntese, propunha a renovação do acordo com a exigência de reajuste das cláusulas econômicas conforme os índices inflacionários do DIEESE (Departamento Intersindical de Estatística e Estudos Socioeconômicos).

A Petrobras respondeu ao grupo petroleiro no dia 22 de maio. Sua proposta eliminava cerca de 30 cláusulas do acordo anterior, entre as quais as que se referiam aos direitos de assistência médica para aposentados e à limitação da atividade sindical. As duas Federações presentes na reunião opuseram-se à Petrobras. Segundo o coordenador da FUP, José Maria Rangel, a proposta da atual gestão da empresa tinha como objetivo abrir o caminho para a privatização total por meio da retirada de direitos "e também praticamente aniquilar o movimento sindical. Por isso nós temos que resistir e participar das assembleias rejeitando essa proposta com disposição de luta, que será necessário." O diretor da Federação Nacional dos Petroleiros (FNP), Adaedson Costa, interpretou a proposta de modo semelhante: "Essa é uma pauta da alta direção da empresa para acabar com os direitos dos trabalhadores e vender o refino e tudo que for possível a preço vil"'13.

Frente à proposta da empresa, os petroleiros decidiram não participar das reuniões seguintes marcadas para 27 e 28 de maio. Em vez disso, convocaram assembleias nas bases com o indicativo de aprovar o estado de greve ${ }^{14}$.

As assembleias foram realizadas nas semanas seguintes. Em todas as bases, os/as empregados/as negaram a proposta da Petrobras ${ }^{15}$ e aprovaram a paralisação para o dia 14 de junho, juntando-se aos protestos contra a reforma da previdência. Nesse dia as bases entraram em greve por todo o país, engrossando os números da greve geral. Entretanto, a ação foi motivada, também, contra o desmonte do acordo coletivo dos/as empregados/as. Assim, a FUP se manifestou de modo oficial:

Além de impedir o fim da Previdência Pública, a categoria petroleira se mobiliza contra a privatização do Sistema Petrobras, em defesa da soberania nacional e por políticas públicas que levem à retomada da atividade econômica, gerando empregos, com trabalho decente e renda digna ${ }^{16}$.

12 A campanha de 2019 foi marcada desde o início por fatores incomuns, dentre os quais se destaca a atuação conjunta das Federações que representam a categoria petroleira: a Federação Única dos Petroleiros (FUP) e a Federação Nacional dos Petroleiros (FNP). As Federações negociavam o acordo separadamente. A FUP representa 13 sindicatos da categoria petroleira, a FNP tem cinco sindicatos em sua base.

13 Matéria publicada no sítio da FUP. Disponível em: <https://www.fup.org.br/ultimas-noticias/item/24019petrobras-apresenta-proposta-de-venda-da-empresa.>. Acesso em: 16 abr. 2020.

14 Os indicativos dos sindicatos para as assembleias eram: "Rejeição da proposta de Acordo Coletivo apresentada pela Petrobras e subsidiárias; Participação na greve geral do dia 14 de junho; Aprovação de Estado de Greve; Aprovação de Estado de Assembleias Permanentes". Disponível em: <https://www.fup.org.br/ultimas-noticias/ item/24032-todos-as-assembleias-para-reafirmar-nenhum-direito-a-menos. $>$. Acesso em: 16 abr. 2020.

15 Disponível em: <https://www.fup.org.br/ultimas-noticias/item/24073-contraproposta-fake-e-rejeitada-porunanimidade.>. Acesso em: 16 abr. 2020.

16 Disponível em: <https://www.fup.org.br/ultimas-noticias/item/24098-petroleiros-iniciam-greve-em-oitoestados-do-pais. >. Acesso em: 16 abr. 2020. 
A realização das assembleias assentou o entendimento, para a base, de que o objetivo da gestão era reduzir os direitos para facilitar a privatização e, segundo os petroleiros, as propostas da empresa provam isso.

O Acordo Coletivo, que vem sendo renovado na luta pela categoria desde 2013, tornou-se peça fundamental na disputa ideológica que a gestão está travando com os trabalhadores. O recado foi dado quando a empresa tenta dizimar capítulos inteiros, como os de segurança no emprego e de relações sindicais. ${ }^{17}$

Simultaneamente às tensas negociações acerca do acordo coletivo, no dia $1 .^{\circ}$ de julho, os petroleiros acionaram a justiça contra a venda de oito das treze refinarias da estatal ${ }^{18}$. Tendo como pano de fundo o resultado das assembleias e a paralisação do dia 14 de junho, a gestão da Petrobras assentiu reunir-se com os petroleiros para pactuarem um novo acordo a partir do dia 25 de junho. As negociações seguiram-se entre 27 de junho e 3 de julho, mas com poucas alterações em relação à proposta inicial da empresa, permaneceu a divergência e, nas assembleias, a base rejeitou a segunda proposta da empresa. "As assembleias foram concluídas nesta sexta-feira, 19, em todas as bases da FUP. A afrontosa proposta dos gestores de 1\% de reajuste salarial foi rejeitada por $100 \%$ da categoria." ${ }^{19}$ As negociações foram retomadas em 8 de agosto. (A Tabela 1 apresenta a terceira proposta da empresa, que também foi rejeitada pelos/ as empregados da Petrobras).

Como as Federações recusaram a terceira proposta, a empresa solicitou mediação do TST no dia 26 de agosto, onde as negociações tomaram um novo rumo. As Federações solicitaram o prolongamento da negociação que foi acatado pelo tribunal.

Apesar de a mediação ter sido pedida pela Petrobras, os gestores não aceitaram a proposta das federações de prorrogar o Acordo Coletivo e manter o processo de discussão em mesa de negociação, na própria empresa. Diante da intransigência da Petrobras, o ministro do TST também propôs que a empresa prorrogue $\mathrm{o} A C \mathrm{~T}$ e dê continuidade à mediação no Tribunal. ${ }^{20}$

O TST propôs prorrogação das negociações até dia 27 de setembro, vindo a mediar uma mesa de negociação no dia 10 de setembro. As Federações formaram uma contraproposta com ameaça de greve em caso de intransigência por parte da empresa ${ }^{21}$.

No dia 26/09, a FUP protocolou no TST itens que, se aceitos, melhoram significativamente a proposta do TST, mantendo os direitos da categoria. Sendo assim, a FUP construiu o calendário de apreciação da proposta de ACT com os seguintes indicativos: Rejeição da proposta apresentada pelo TST no dia 19/09; Aprovação

17 Disponível em: <https://www.fup.org.br/ultimas-noticias/item/24165-a-saida-e-coletiva.>. Acesso em: 16 abr. 2020.

18 "Em resposta ao comunicado que a Petrobras fez ao mercado na última sexta-feira, 28, dando início ao processo de venda de quatro das oito refinarias da empresa que estão sendo privatizadas, os sindicatos da FUP ingressaram com Ação Popular para barrar a entrega dos ativos". Disponível em: <https://www.fup.org.br/ultimas-noticias/ item/24154-sindipetros-da-fup-entram-com-acao-na-justica-contra-venda-de-refinarias-da-petrobras. $>$. Acesso em: 16 abr. 2020.

19 Disponível em: <https://www.fup.org.br/ultimas-noticias/item/24220-rejeicao-100-para-a-proposta-de-1-dapetrobras. $>$. Acesso em: 16 abr. 2020.

${ }_{20}$ Disponível em: <https://www.fup.org.br/ultimas-noticias/item/24342-que-papelao-petrobras.>. Acesso em: 16 abr. 2020.

${ }^{21}$ A Petrobras emitiu uma única nota, ao longo de toda negociação, no dia 1. ${ }^{\circ}$ de outubro de 2019: "A Petrobras reforça seu compromisso com a transparência na comunicação e que seu objetivo sempre foi chegar na melhor proposta para os empregados, mas sem colocar em risco a saúde financeira e sustentabilidade da companhia". Disponível em: <https://www.investidorpetrobras.com.br/ptb/15788/9512_713718.pdf.>. Acesso em: 18 abr. 2020. 
dos itens encaminhados ao TST, em 26/09, como melhoria à proposta do Tribunal; Condicionar a assinatura da eventual aprovação das propostas às assinaturas dos acordos coletivos de trabalho das subsidiárias e da Araucária Nitrogenados; Caso não ocorra negociação, greve a partir de zero hora do dia $26 / 10 .{ }^{22}$

\section{TABELA 1- TERCEIRA PROPOSTA DA PETROBRAS PARA O ACORDO COLETIVO DE} TRABALHO DE 2019²3.

\begin{tabular}{|c|c|c|}
\hline Cláusulas mantidas & Cláusulas alteradas (implicando perdas) & Cláusulas excluídas \\
\hline $\begin{array}{l}\text { 3. Gratificação de férias. } \\
\text { 5. Gratificação de Campo } \\
\text { Terrestre de Produção. } \\
\text { 12. Manutenção das } \\
\text { cláusulas de segurança no } \\
\text { emprego. } \\
\text { 15. Segurança Industrial e } \\
\text { Saúde Ocupacional. } \\
\text { 16. Comissões permanen- } \\
\text { tes para acompanhamento } \\
\text { do ACT, SMS (Segurança, } \\
\text { Meio Ambiente e Saúde) e } \\
\text { AMS (Assistência Médica } \\
\text { Suplementar do Sistema } \\
\text { Petrobras). } \\
\text { 20. Manutenção da data- } \\
\text {-base. }\end{array}$ & $\begin{array}{l}\text { 1. Reajuste de } 70 \% \text { do INPC acumulado } \\
\text { no período de } 01 / 09 / 2018 \text { a } 31 / 08 / 2019 . \\
\text { 2. } 13 .^{\circ} \text { salário: perda da antecipação. } \\
\text { 4. Adicional de permanência no Estado do } \\
\text { Amazonas foi abolido para novos empre- } \\
\text { gados. } \\
\text { 6. Pagamento de Horas Extras. } \\
\text { 7. Hora Extra Troca de Turno. } \\
\text { 8. Feriado Turno. } \\
\text { 9. Concessão de Hospedagem e Diárias } \\
\text { para Treinamentos ou Outra Atividade } \\
\text { no Período de Embarque nas Plataformas } \\
\text { Marítimas. } \\
\text { 10. Programa jovem universitário. } \\
\text { 11. Programa de Assistência Multidiscipli- } \\
\text { nar de Saúde. } \\
\text { 14. Jornada de Trabalho. } \\
\text { 17. Liberdades sindicais. } \\
\text { 18. Comissão da tabela de turno industrial. } \\
\text { 19. Comissão para regramento da PLR. } \\
\text { 21. Vigência do ATC. }\end{array}$ & $\begin{array}{l}\text { 13. Promoção por Antiguidade de } \\
\text { Plena para Sênior dos Cargos de } \\
\text { Nível Médio. } \\
\text { - Cláusulas não renovadas: i) co- } \\
\text { missão de anistia; ii) Contratação de } \\
\text { prestadores de serviços; iii) Contra- } \\
\text { tos de prestação de serviços; iv) Con- } \\
\text { tribuição assistencial; v) Divulgação } \\
\text { de processos seletivos; vi) Efetivo de } \\
\text { pessoal; vii) Empregado estudante; } \\
\text { viii) Fiscalização de contratos de } \\
\text { prestação de serviços; ix) Homologa- } \\
\text { ção de rescisão contratual; x) Licen- } \\
\text { ças para exercício de mandato ele- } \\
\text { tivo; xi) Motoristas; xii) Política de } \\
\text { admissão de novos empregados; xiii) } \\
\text { Preservação dos acordos coletivos } \\
\text { de trabalho regionais; xiv) Programa } \\
\text { de complementação educacional; xv) } \\
\text { programa de resgate e redefinição do } \\
\text { potencial laborativo. }\end{array}$ \\
\hline
\end{tabular}

Nas assembleias, os/as empregados/as, majoritariamente, seguiam rejeitando a proposta do TST. Após reuniões deliberativas com massiva presença da base, a proposta foi rejeitada com a decisão de entrar em greve a partir do dia 26 de outubro ${ }^{24}$.

No entanto, a aprovação da greve gerou nova proposta da Petrobras com melhoria dos itens apontados pelas Federações e, finalmente, o ACT foi assinado em 4 de novembro, após quase seis meses de tensas negociações e com validade de apenas um ano, quando o costume era a vigência de dois anos. $\mathrm{O}$ acordo foi assinado no tribunal, fato incomum na história do grupo que, ao longo de sua trajetória, criou a tradição de construir seus próprios direitos evitando a possibilidade de arbítrio da Justiça do Trabalho ${ }^{25}$.

A tradição e a experiência de luta associadas ao poder de organização dos/as trabalhadores/as deram ao grupo a força necessária para obstar uma significativa perda de

${ }^{22}$ Disponível em: <https://www.fup.org.br/ultimas-noticias/item/24460-manter-a-unidade-e-manter-os-direitos.>. Acesso em: 16 abr. 2020.

23 Fonte: "Terceira proposta da Petrobras para ACT 2019". Disponível em: <https://www.fup.org.br/ultimasnoticias/item/24275-petrobras-apresenta-terceira-contraproposta-de-act-que-mantem-graves-cortes-dedireitos.>. Acesso em: 16 abr. 2020. Os números das cláusulas são os mesmos apresentados no documento.

24 Disponível em: <https://www.fup.org.br/ultimas-noticias/item/24541-fup-comunica-a-petrobras-e-ao-tstresultado-das-assembleias-e-aguarda-posicionamento-sobre-melhoria-da-proposta-de-act.>. Acesso em: 16 abr. 2020.

25 Disponível em: <https://www.fup.org.br/ultimas-noticias/item/24502-o-que-garante-a-data-base.>. Acesso em: 16 abr. 2020. 
direitos. O ACT 2019-2020, certamente, não preservou todos os direitos e benefícios dos acordos anteriores $^{26}$, tampouco a atual gestão da Petrobras conseguiu emplacar o desmonte pretendido.

A observação desses eventos nos permite afirmar que o acordo coletivo é antes a expressão de uma relação de força entre o capital e o trabalho, do que uma pacífica conciliação de interesses. Afirmar que os acordos entre o capital e o trabalho são sempre atos de capitulação dos sindicatos equivale a negligenciar o estatuto real das relações de trabalho. Essas são intrinsecamente conflitivas e, ao mesmo tempo, incluem a possibilidade de se afirmar acordos que,pela própria natureza das relações de trabalho, são provisórios. Ou seja, o caráter provisório dos acordos se impõe porque esses não escapam da dinâmica do conflito de classe. Em outras palavras, os acordos são encobertos, permanentemente, por tensões e são garantidos, ou não, por meio da força (SANTOS, 1979). No caso observado, o grupo de trabalhadores e de trabalhadoras mostrou ter um conjunto diversificado de recursos de poder (SCHMALZ; LUDWIG; WEBSTER, 2018) que foi mobilizado para sustar as pretensões da atual gestão da Petrobras de eliminar uma parte significativa dos direitos estabelecidos no acordo coletivo de trabalho dos petroleiros e das petroleiras.

\section{O FOCO DE TENSÕES NA NEGOCIAÇÃO DO ACT 2019-2020}

O pretendido desmantelamento do acordo coletivo, implicando a perda de direitos e a precarização das relações de trabalho para os trabalhadores da Petrobras, tal como demonstra a Tabela 1, por si só poderia resultar em um forte enfraquecimento da organização sindical. Porém, o foco de tensões esteve associado à Assistência Médica Suplementar do Sistema Petrobras (AMS).

A AMS é o "serviço de assistência de saúde suplementar que atende 246 mil beneficiários da empresa e subsidiárias" e foi criada em 1975 para dar assistência médica especializada aos trabalhadores do sistema Petrobras. Esse serviço especial resulta "do elevado índice de adoecimentos e acidentes na indústria do petróleo". Atualmente, esse plano assiste aos "trabalhadores da ativa, aposentados, pensionistas e seus dependentes". Trabalhadores e aposentados contribuem com até 30\% dos custos totais de manutenção do plano assistencial, a Petrobras arca com os $70 \%$ restantes $^{27}$.

Essa relação de custeio da AMS foi ameaçada ainda durante o governo Temer. Em 18 de janeiro de 2018, a Resolução 23 da Comissão Interministerial de Governança Corporativa de Participações Societárias da União (CGPAR) modificava as regras dos planos de assistência médica das empresas estatais. Após ser regulamentada, em 5 de abril, as empresas estatais deveriam vetar, nos acordos coletivos, as cláusulas que garantiam direitos à assistência médica, além de modificar o custeio para os aposentados. No caso da Petrobras, os trabalhadores que se aposentassem a partir daquela data não teriam mais acesso aos serviços da AMS, o direito ficava restrito aos trabalhadores da ativa. Ademais, os trabalhadores da ativa e os aposentados

\footnotetext{
${ }^{26}$ As perdas se concentraram nas cláusulas econômicas. Dentre os principais prejuízos, destacam-se: a antecipação do $13 .^{\circ}$ salário foi excluída do acordo; as cláusulas sobre o direito de férias foram modificadas; os adicionais, vinculados à remuneração líquida, deixaram de sofrer reajuste automático pelo IPCA; as cláusulas sobre "Feriado Turno" remuneravam os feriados em 100\%, passou-se a praticar 50\%; as horas extras eram pagas com um sobrevalor de 100\%, caiu para 75\%; o programa de complementação educacional, cláusula 26 ACT 2017 2019, foi abolido.

27 Disponível em: <https://fup.org.br/ultimas-noticias/item/25226-diretoria-da-petrobras-age-na-surdina-paraprivatizar-gestao-da-ams-com-impactos-de-r-2-bi > ; <https://fup.org.br/ultimas-noticias/item/23119-resolucao23-e-empregados-da-petrobras.>. Acesso em: 18 abr. 2020.
} 
teriam que arcar com um aumento de custos para manter a AMS, a contribuição passaria a ser paritária $50 \times 50^{28}$.

Portanto, uma vez regulamentada a Resolução 23, os petroleiros já previram seus efeitos. Sabiam que enfrentariam a tentativa de destruição desses direitos já na próxima campanha reivindicatória. Em agosto de 2018, o assessor jurídico da FUP, Normando Rodrigues, alertava: "A AMS só existe por causa do ACT. Se não estiver protegida por um novo ACT, que enfrente e supere a Res. 23, não haverá saída. Não há alternativa a não ser a mobilização dos empregados da Petrobras, ativos e aposentados, por um ACT 2019 que mantenha a AMS"29.

Como previsto, em 5 de abril de 2019 a Petrobras enviou um documento "informando que irá cobrar dos beneficiários da AMS a equalização do custeio 70x30, de forma unilateral, sem sequer ter discutido essa questão na Comissão de AMS, como prevê o Acordo Coletivo na Cláusula 31" ${ }^{\prime 30}$. Ademais, desconsiderando o ACT 2017-2109, a empresa decidiu estabelecer a cobrança do déficit de 119,5 milhões de reais sobre os custos da AMS referentes ao ano de 2018.

A AMS constitui um fundo vultuoso, por isso é cobiçado pelo mercado privado dos planos de saúde. Segundo a FUP, durante o "Gov. FHC, por exemplo, estava preparada a entrega da AMS para a Golden Cross, e só a mobilização dos trabalhadores impediu”, por meio de uma paralisação de cinco dias em outubro de $2001^{31}$.

Desse modo, a alteração dos custos de 30x70 para 50x50 foi um dos pontos de maior tensão durante a campanha reivindicatória do ACT de 2019. No dia 17 de junho, os petroleiros reuniram-se com os representantes da gestão da empresa para tratar dessa questão e da cobrança dos custos adicionais relativos ao déficit de 2018. Segundo a FUP, a empresa iniciou a cobrança de modo unilateral, descumprindo o ACT: "Em abril deste ano, a empresa enviou documento informando que cobraria dos beneficiários da AMS a equalização do custeio 70x30, de forma unilateral, sem discutir essa questão na Comissão de AMS, como prevê o Acordo Coletivo na Cláusula 31, no Parágrafo $1 .^{0{ }^{\prime \prime 32}}$. No acordo assinado em 4 de novembro, os petroleiros conseguiram manter a relação de custeio $70 \times 30$ e a existência de uma comissão permanente para tratar das questões da AMS.

Outro ponto de tensão foram as questões relativas à organização dos turnos de trabalho. As tabelas impostas pela empresa implicavam uma organização do processo de trabalho com base em "turno ininterrupto nas refinarias". Frente a isso, os petroleiros "tornaram a defender a manutenção das tabelas atuais e sua inclusão no Acordo Coletivo de Trabalho 2019. A Gerência de Gestão de Pessoas, no entanto, insiste na necessidade de novas tabelas de turno, o que tem sido veementemente questionado pelas federações" ${ }^{33}$. Ao fim do acordo uma comissão ficou incumbida de arbitrar mudanças nas tabelas de turno.

28 Disponível em: <https:/fup.org.br/ultimas-noticias/item/23094-governo-altera-regras-de-planos-de-saude-deestatais.>. Acesso em: 18abr. 2020.

29 Disponível em: <https://fup.org.br/ultimas-noticias/item/23119-resolucao-23-e-empregados-da-petrobras.>. Acesso em: 18 abr. 2020.

30 Disponível em: <https://fup.org.br/ultimas-noticias/item/23906-fup-reage-a-mais-uma-medida-arbitraria-dapetrobras.>. Acesso em: 18 abr. 2020.

31 Disponível em: <https://fup.org.br/ultimas-noticias/item/23119-resolucao-23-e-empregados-da-petrobras.>. Acesso em: 18 abr. 2020.

32 Disponível em: <https://www.fup.org.br/ultimas-noticias/item/24126-reuniao-discute-pendencia-do-actanterior-sobre-cobranca-extraordinaria. $>$. Acesso em: 18 abr. 2020.

33 Disponível em: <https://www.fup.org.br/ultimas-noticias/item/24124-reuniao-com-a-petrobras-sobre-tabelasde-turno-prossegue-nesta-quarta;https://www.fup.org.br/ultimas-noticias/item/24146-petrobras-suspendemudancas-na-tabela-de-turno-e-restabelece-regimes-de-trocas-praticados-antes. > . Acesso em: 18 abr. 2020. 
O descumprimento do ACT pela gestão da Petrobras prova o poder discricionário das empresas no trato das regras pactuadas acerca das relações de trabalho (NORONHA, 2000). Não basta que exista um pacto para que a lei se cumpra, as relações de trabalho são, estruturalmente, relações de poder (SCHMALZ; LUDWIG; WEBSTER, 2018). Assim, o que se observa é uma tendência da empresa buscar reduzir custos, por meio do corte de direitos ou negligenciando a lei ou o acordo. Essa prática prosseguirá até que encontre resistência. Como o poder de justiça do Estado, capaz de fazer a lei ser cumprida, não é onipresente, a primeira reação deve vir dos trabalhadores, quando protegidos por sindicatos, são essas entidades que atuam contra o poder discricionário das empresas ou cobrando o cumprimento do que foi pactuado (SANTOS, 1979).

Foi denunciando o descumprimento do ACT, recém-assinado, que, em 22 de novembro de 2019, os petroleiros alertaram que entrariam em greve entre os dias 25 e 29 em protesto

para exigir da Petrobras o cumprimento do Acordo Coletivo de Trabalho (ACT) [...]. Além de demissões e transferências em massa, a diretoria da Petrobras incluiu metas de segurança, saúde e meio ambiente (SMS) como critérios para pagamento de bônus e concessão de vantagens. Tais ações, de acordo com o coordenador geral da FUP, José Maria Rangel, ferem as cláusulas 41 e 86 do ACT, que tratam de trabalhadores efetivos, e o parágrafo 9.0 da cláusula 73 do mesmo acordo, que veda o uso de metas de SMS em avaliações ${ }^{34}$.

No dia seguinte a essa declaração, o TST declarou a greve ilegal, caso viesse ocorrer desabastecimento, mas os petroleiros mantiveram a mobilização e entraram em greve no dia 25 e saíram no dia 27. Um ministro do TST decidiu, monocraticamente, que a greve era ilegal, tendo ocorrido pouco tempo após a assinatura do ACT, e impôs aos sindicatos multas milionárias para cada dia ${ }^{35}$ parado.

\section{O CARÁTER NEOLIBERAL DA ATUAL GESTÃO DA PETROBRAS}

A descrição do processo de negociação do ACT 2019-2020 dos petroleiros com a Petrobras reforça o entendimento de que as relações entre o capital e o trabalho são constituídas, estruturalmente, por tensões. No entanto, se comparados aos acordos anteriores, o comportamento da atual gestão destoa. Mesmo sob o governo Temer, que colocou em prática uma série de reformas que enfraqueceu a proteção social vinculada ao trabalho, não se viu uma tentativa tão agressiva com o objetivo de retirar direitos. Como qualificar as atitudes da atual gestão da Petrobras, que se caracterizaram pelos seguidos descumprimentos do acordo coletivo e pela clara tentativa de excluir uma série de direitos dos/as empregados/as?

Não é novidade que a preservação ou a ampliação dos direitos do trabalho, e a proteção social que eles garantem, não constam nos planos do atual governo. Desde a eleição o atual presidente deu declarações públicas de que os trabalhadores deveriam escolher entre ter direitos

34 Disponível em: <https://www.fup.org.br/ultimas-noticias/item/24652-comunicado-a-imprensa-petroleirosparalisam-atividades-pelo-cumprimento-do-acordo-coletivo-fechado-com-a-petrobras.>. Acesso em: 18 abr. 2020.

35 A categoria saiu da greve, mas a mobilização continuou por meio de campanhas solidárias como doação de sangue, limpeza de praias atingidas por derramamento de óleo no Nordeste e a distribuição de combustível e gás a preços de produção. Antes do fím de 2019, o pleno do TST derrubou a medida monocrática do ministro Ives Gandra Martins Filho. Na greve de 2020, contra a privatização e as demissões na Fábrica de Fertilizantes Nitrogenados do Paraná, o ministro usou do mesmo expediente, declarou a greve ilegal com aplicação de multas milionárias. Entretanto, tendo a experiência da derrota do ministro pelo pleno do tribunal, a categoria não voltou atrás e continuou em greve. O ministro, então, retirou a própria decisão e recomendou uma mediação para o conflito. 
ou ter trabalho. Essa é, aliás, a mesma opinião do ministro da economia, Paulo Guedes, quem, durante a greve dos petroleiros em novembro de 2019, disse que se a empresa fosse privada ele demitiria todos os grevistas ${ }^{36}$. Ou seja, a greve não seria um direito do trabalhador. E uma visão antissindical também pode ser percebida no discurso do atual presidente da Petrobras, indicado para o cargo pelo ministro da economia.

Na ocasião de uma audiência pública no Senado Federal em agosto de 2019, o atual presidente da empresa disse que pretendia encerrar as atividades da Petrobras no Uruguai ${ }^{37}$, também, por lá existir um "sindicato voraz" que, com o apoio do governo uruguaio, sempre conseguiu aumentos salariais que acabaram por contribuir com os prejuízos arcados pela empresa.

\begin{abstract}
Na véspera da Cúpula do MERCOSUL, eu tive uma reunião com o Presidente Tabaré Vasquez do Uruguai, e acertei com ele a devolução das concessões de distribuição de gás da Petrobras no Uruguai. A Petrobras é o grande distribuidor de gás no Uruguai desde 2004. Por que nós fizemos isso? Esse é um investimento que estava fadado a dar prejuízo sempre, como de fato deu, por quê? A Petrobras comprava gás natural da Argentina a preço de mercado e cobrava dos consumidores uruguaios um preço tabelado e subsidiado. Pagava o fornecedor de gás natural em sete dias, recebia de seus clientes em 40 dias. Ainda tinha um sindicato voraz, apoiado pelo governo uruguaio, qualquer negociação era tripartite - a empresa, o governo e o sindicato - e o governo sempre apoiava o sindicato. Então tivemos um aumento brutal de salários, em dólares, que afogaram a empresa ${ }^{38}$.
\end{abstract}

Por outro lado, o plano de desinvestimento aplicado na gestão da empresa desde a "crise de credibilidade", com aprofundamento drástico na gestão de Pedro Parente, durante a maior parte do governo de Michel Temer, foi incrementado por outro objetivo imposto pela atual gestão. Trata-se do processo de desmonopolização do setor de petróleo e gás, que é desenvolvido por meio da privatização de empresas subsidiárias da Petrobras. A venda das subsidiárias implica na entrada de empresas privadas no setor, que, segundo a visão de seu atual presidente, tem como efeito criar um ambiente de concorrência em um setor monopolizado.

O desinvestimento, em lugar de ser um desmonte, é uma contribuição, não só para a Petrobras, mas para o crescimento econômico do Brasil. A Petrobras era responsável por $98 \%$ da capacidade de refino, quer dizer, uma posição, uma verdadeira anomalia. Por que, os senhores que representam, as senhoras que representam o povo brasileiro, num regime democrático, deveriam abominar monopólios, como eu abomino? O monopólio é incompatível com o funcionamento de uma sociedade livre e democrática. Do ponto de vista econômico, ele gera muitas distorções que contribuem para minar o crescimento econômico de um país [...]. A mesma coisa se dá no mercado de gás. A Petrobras, com toda essa dominância no mercado de gás, não ganhou nada. Pelo contrário, só prejuízos. E prejudicou o Brasil. Quando nós fomos ao CADE, voluntariamente fazer um acordo para abrir esse mercado para a competição, foi

36 Disponível em: <https://economia.uol.com.br/noticias/estadao-conteudo/2019/11/25/guedes-sugere-quedemitiria-grevistas-se-petrobras-fosse-empresa-privada.htm.>. Acesso em: 18 abr. 2020.

37 Desde abril e maio as federações se solidarizavam com os trabalhadores uruguaios contra demissões e por respeito aos seus direitos. No dia 10 de junho os petroleiros uruguaios entraram em greve contra os ataques impetrados pela empresa retirando direitos dos trabalhadores uruguaios. Disponível em: <http://www. fnpetroleiros.org.br/noticias/5329/mocao-de-repudio-contra-medida-da-justica-uruguaia $>$.; $\quad<$ https://www.fup. org.br/ultimas-noticias/item/24077-todo-apoio-a-greve-dos-petroleiros-uruguaios.>. Acesso em: 18 abr. 2020.

38 Roberto Castello Branco, presidente da Petrobras, na Comissão de Infraestrutura (CI), que realizou audiência pública sobre a privatização de refinarias, fábricas de fertilizante e malhas dutoviárias da Petrobras no dia 13 de agosto de 2019. Disponível em: <https:/www.youtube.com/watch?v=PDTS5OtIvLI.>. Acesso em: 21 abr. 2020. 
pensando, não só na Petrobras, que vai passar a ter competidores no mercado, então vai ser compelida a ser eficiente, como no Brasil, que vai ter mais investimentos, maior geração de empregos, vai ter uma verdadeira indústria de gás natural ${ }^{39}$.

Segundo a atual gestão, uma vez criado esse ambiente competitivo, a estatal teria que buscar, necessariamente, maior eficiência como empresa. Para ser bem-sucedida, a estratégia que visa criar concorrência no setor de petróleo e gás parece ter como premissa o rebaixamento dos custos com a força de trabalho, por isso a atitude antissindical da atual gestão, que se expressou tanto no caso uruguaio quanto no caso brasileiro.

Atitudes e discursos hostis aos sindicatos fizeram parte da ascensão política do neoliberalismo desde a onda de greves dos anos 1968-1969, na Europa continental, até o desmantelamento de poderosos sindicatos como o dos controladores de tráfego aéreo, em 1981 pelo governo Reagan nos EUA, e dos mineiros, em 1984, pelo governo Thatcher (HARVEY, 2008). Nessas décadas, "começou em todas as democracias ocidentais uma marginalização mais ou menos agressiva dos sindicatos" (STREECK, 2018). Por vias muito semelhantes às que descrevemos acima, reformar equivalia a eliminar direitos:

\begin{abstract}
Iniciaram-se, paralelamente, reformas dos mercados de trabalho e dos sistemas de seguridade social no nível mundial - na maior parte das vezes, graduais, mas não menos incisivas. Essas reformas conduziram - sob o manto de uma "flexibilização", alegadamente havia muito necessária, das instituições e da "ativação" do potencial da mão de obra - a uma profunda revisão do Estado de bem-estar social das décadas pósguerra, justificada, cada vez mais, também, com a expansão dos mercados para além das fronteiras nacionais, com a chamada "globalização" (STREECK, 2018, p. 76).
\end{abstract}

Orientadas pela regra de ouro da concorrência e da competição, as práticas da atual gestão têm provocado uma verdadeira reorganização do setor de petróleo e gás no Brasil. Durante os dois anos e meio de governo Temer e o primeiro ano do governo Bolsonaro, a Petrobras vendeu parcela significativa de seu patrimônio:

BR Distribuidora; Transportadora Associada de Gás (TAG); Nova Transportadora do Sudeste (NTS); Petroquímica Suape (PE); Usina de Biocombustível Belém Bioenergia Brasil (AM); Usina de Biocombustível Guarani (7 plantas em SP e 1 na África); Termelétricas Celso Furtado e Rômulo Almeida (BA); Participações em campos do Pré-Sal: Carcará, Tartaruga Verde, Iara e Lapa; 34 campos terrestres; 10 concessões nas Bacias de Campos e Santos; 7 sondas de perfuração; e diversos ativos no exterior ${ }^{40}$.

Ao mesmo tempo, como parte dessa racionalidade, prossegue-se a tentativa de desmonte da proteção social dos trabalhadores da empresa. Apesar de terem demonstrado poder de organização para impedir o desmantelamento do acordo coletivo dos/as empregados/ as, os petroleiros estão expostos a um contexto muito semelhante ao vivido pelos trabalhadores brasileiros nos anos 1990. Essa década foi marcada por uma forte desregulamentação do mercado de trabalho cujos efeitos contribuíram para ampliar ainda mais a sua heterogeneidade, diminuindo as margens da estreita "sociedade salarial" no Brasil.

\footnotetext{
${ }^{39}$ Roberto Castello Branco, presidente da Petrobras, em audiência pública sobre a privatização de refinarias, fábricas de fertilizante e malhas dutoviárias. Disponível em: <https:/www.youtube.com/watch?v=PDTS5OtIvLI.>. Acesso em: 21 abr. 2020.

40 Disponível em: <https://www.fup.org.br/ultimas-noticias/item/24450-edicao-especial-da-fup-resgata-historiade-resistencia-da-petrobras.>. Acesso em: 18 abr. 2020.
} 


\section{6.}

\section{CONCLUSÃO}

Tomando por base o caráter histórico da ação coletiva das trabalhadoras e dos trabalhadores da Petrobras, acentuamos as feições de classe dessa relação, marcada pelo conflito, com maior ou menor tensão, dependendo do contexto político. Esse conflito se deve ao fato de a Petrobras ser uma empresa de capital misto controlada pelo Estado brasileiro e gerida pelos grupos políticos que controlam o poder executivo federal, uma vez que a indicação do presidente da empresa é uma prerrogativa desse poder. Assim, as tensões que aparecem entre os petroleiros e a Petrobras, podem assumir a forma de um conflito, às vezes velado, às vezes explícito, entre as organizações sindicais dos trabalhadores e trabalhadoras petroleiros e o grupo político no poder.

As tensões na relação entre os trabalhadores e a Petrobras manifestaram-se intensamente durante o processo de negociação que resultou no ACT 2019-2020. Com base em dados extraídos de diversos meios (sites da FUP, da Petrobras e portais de notícias), realizamos uma descrição detalhada desse processo, destacando seus interstícios (propostas e contrapropostas, assembleias e paralisações, mediação do TST, alongamento da negociação, assinatura do acordo, greve e multa do TST), o que nos permitiu evidenciar uma permanente tensão antes, durante e depois do acordo coletivo de trabalho. Mais uma vez, é possível afirmar que o conflito é uma característica perene nas relações entre os petroleiros e a Petrobras, ora latente, ora manifesto. A própria dinâmica do processo de negociação (aqui analisada) mostrou que o acordo não elimina as tensões, tampouco o conflito. E isso não é uma exclusividade da atual conjuntura, conforme abordamos por meio da reconstrução do histórico da ação coletiva petroleira.

A análise do foco das tensões do processo de negociação demonstrou, além disso, que a tentativa de esvaziar o acordo coletivo por meio da retirada de direitos e de benefícios dos/as empregados/as, com o potencial de enfraquecer os seus sindicatos, especificamente, por meio da alteração e/ou exclusão de cláusulas de representação no acordo coletivo, a resistência a tudo isso, só foi possível pela capacidade dos trabalhadores e das trabalhadoras desferirem um conjunto variado de recursos de poder para defender os seus direitos derrotando a ofensiva empresarial.

O impetuoso movimento da atual gestão da Petrobras com uma proposta de eliminar os diretos de seus empregados e criar um ambiente competitivo no setor de petróleo e gás foi qualificado por meio de uma aproximação com uma racionalidade neoliberal. $\mathrm{O}$ discurso do atual presidente da empresa evidenciou o casamento com ideias e práticas neoliberais, tanto no que se refere à gestão dos negócios - por meio de um plano estratégico que visa propiciar uma maior competitividade ao setor por meio da privatização de parte do patrimônio da empresa - quanto em relação ao tratamento dispensado aos direitos dos empregados - em que se destacou uma prática antissindical, visando o enfraquecimento das entidades representativas dos trabalhadores.

\section{REFERÊNCIAS}

ALMEIDA, M. H. T. Crise econômica e interesses organizados: o sindicalismo no Brasil dos anos 1980. São Paulo: Edusp, 1996.

ALVES, G. Trabalho e sindicalismo no Brasil: um balanço crítico da "década neoliberal" (19902000). Revista de Sociologia e Política, Curitiba, v.19, p.71-94, 2002.

BRANT, V. C. Paulínia, petróleo e política. Campinas: Sindicato dos Petroleiros de Paulínia e Campinas, Cebrap, 1990. 
CARDOSO, A. A década neoliberal e a crise dos sindicatos no Brasil. São Paulo, Boitempo, 2003.

CERQUEIRA, B. S. Política fiscal, demanda agregada, crescimento e crise: o investimento federal e o investimento da Petrobras no período 2003-2015. Rio de Janeiro: I.E./UFRJ, 2016. Disponível em: https://www.ie.ufrj.br/images/IE/TDS/2016/TD_IE_027_2016_CERQUEIRA. pdf. Acesso em: 11 jul. 2019.

GOMES, A. M. de C. A invenção do trabalhismo. Rio de Janeiro: FGV, 2005.

HARVEY, D. O neoliberalismo: história e implicações. São Paulo: Loylola, 2008.

KREIN, J. D; TEIXEIRA, M. As controvérsias das negociações coletivas nos anos 2000 no Brasil. In: OLIVEIRA, R. V.; BRIDI, M. A.; FERRAZ, M. (Org.). O sindicalismo na era Lula: paradoxos, perspectivas e olhares. Belo Horizonte: Fino Traço, 2016, p. 213-246.

LÊNIN, V. I. O que fazer? São Paulo: Hucitec, 1978.

LOUREIRO, I.; TROJBICZ, B. Rupturas, continuidades e gradualismo nas políticas de petróleo no Brasil: 1995 a 2010. Organizações \& Sociedade, Salvador, v. 25, n. 85, 2018.

MORAIS, J. M. Petrobras: crise financeira e de credibilidade e recuperação recente. IPEA, Radar, n. 53, 2017. Disponível em: https:/www.ipea.gov.br/radar/temas/industria/678petrobras-crise-financeira-e-de-credibilidade-e-recuperacao-recente. Acesso em: 9 set. 2020.

MENDES, D. A ação sindical petroleira nos governos do partido dos trabalhadores (20032016). Temáticas, Campinas, v. 27, n. 53, p. 225-250, 2019. Disponível em: https://econtents. bc.unicamp.br/inpec/index.php/tematicas/article/view/11607. Acesso em: 22 abr. 2020.

NORONHA, E. G. O modelo legislado de relações de trabalho no Brasil. Dados, v. 43, n. 2, p. 241-290, 2000.

OLIVEIRA, F. Política numa era de indeterminação: opacidade e reencantamento. In: OLIVERIA, F.; RIZEK, C. S. (Org.). A era da indeterminação. São Paulo: Boitempo, 2007.

PARANHOS, M. da S. Mobilização e ação sindical: a Federação Única dos Petroleiros (FUP) e a negociação coletiva para o acordo 2013-2015.2016. Tese (Doutorado em Sociologia) Universidade Federal do Rio de Janeiro, Rio de Janeiro, 2016.

ROMÃO, F. L. A greve do fim do mundo: petroleiros 1995 - expressão fenomênica da crise fordista no Brasil.2006. Tese (Doutorado em Sociologia) - Universidade Estadual de Campinas, Campinas, 2006.

SANTOS, W. G. dos. Cidadania e justiça: política social na ordem brasileira.Rio de Janeiro: Campus, 1979.

SCHMALZ, S.; LUDWIG, C.; WEBSTER, E. The power resources approach: developments and challenges. Global Labour Journal, v. 9, n. 2, p. 113-134, 2018.

SILVER, B. J. Forces of Labor: Workers' movements and globalization since 1870.Cambridge: Cambridge University Press, 2003.

STREECK, W. Tempo comprado: a crise adiada do capitalismo democrático. São Paulo: Boitempo, 2018.

THOMPSON, E. P. A formação da classe operária inglesa: a árvore da liberdade. Rio de Janeiro/São Paulo: Paz e Terra, 2019. v. 1.

WRIGHT, E. O. Working-class Power, capitalist-class interests and class compromise. American Journal of Sociology, v. 105, n. 4, p. 957-1002, 2000. 